\title{
Ultrafast X-ray Photochemistry at European XFEL: Capabilities of the Femtosecond X-ray Experiments (FXE) Instrument
}

\author{
Dmitry Khakhulin ${ }^{1,2, *}$, Florian Otte ${ }^{1,3}$, Mykola Biednov ${ }^{1}$, Christina Bömer ${ }^{1}$, Tae-Kyu Choi ${ }^{1}$ (i), \\ Michael Diez ${ }^{1}$, Andreas Galler ${ }^{1}$, Yifeng Jiang ${ }^{1}{ }^{1}$, Katharina Kubicek ${ }^{1}$, Frederico Alves Lima ${ }^{1}$,

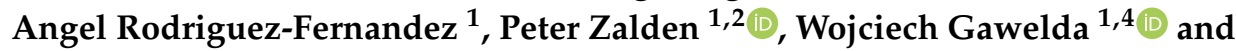 \\ Christian Bressler ${ }^{1,2, *}$ \\ 1 European XFEL, Holzkoppel 4, 22869 Schenefeld, Germany; florian.otte@xfel.eu (F.O.); \\ mykola.biednov@xfel.eu (M.B.); christina.boemer@xfel.eu (C.B.); tae.kyu.choi@xfel.eu (T.-K.C.); \\ michael.diez@xfel.eu (M.D.); andreas.galler@xfel.eu (A.G.); yifeng.jiang@xfel.eu (Y.J.); \\ katharina.kubicek@xfel.eu (K.K.); frederico.lima@xfel.eu (F.A.L.); \\ angel.rodriguez-fernandez@xfel.eu (A.R.-F.); peter.zalden@xfel.eu (P.Z.); wojciech.gawelda@xfel.eu (W.G.) \\ 2 The Hamburg Centre for Ultrafast Imaging, Luruper Chaussee 149, 22761 Hamburg, Germany \\ 3 Otto-Hahn-Str. 4, Fakultät für Physik, Technical University Dortmund, 44227 Dortmund, Germany \\ 4 Faculty of Physics, Adam Mickiewicz University, ul. Uniwersytetu Poznańskiego 2, 61-614 Poznań, Poland \\ * Correspondence: dmitry.khakhulin@xfel.eu (D.K.); christian.bressler@xfel.eu (C.B.)
}

Received: 30 December 2019; Accepted: 30 January 2020; Published: 3 February 2020

Featured Application: Femtosecond X-ray Experiments on photoexcited chemical systems deliver a portfolio of new observables including electronic, spin and nuclear dynamics. This is achieved by exploiting structural tools like XANES, EXAFS, WAXS/SAXS, RIXS and X-ray Raman Spectroscopy in the time domain with an optical laser pulse driving the reaction under investigation.

\begin{abstract}
Time-resolved X-ray methods are widely used for monitoring transient intermediates over the course of photochemical reactions. Ultrafast X-ray absorption and emission spectroscopies as well as elastic X-ray scattering deliver detailed electronic and structural information on chemical dynamics in the solution phase. In this work, we describe the opportunities at the Femtosecond X-ray Experiments (FXE) instrument of European XFEL. Guided by the idea of combining spectroscopic and scattering techniques in one experiment, the FXE instrument has completed the initial commissioning phase for most of its components and performed first successful experiments within the baseline capabilities. This is demonstrated by its currently $115 \mathrm{fs}$ (FWHM) temporal resolution to acquire ultrafast $X$-ray emission spectra by simultaneously recording iron $K \alpha$ and $K \beta$ lines, next to wide angle $\mathrm{X}$-ray scattering patterns on a photoexcited aqueous solution of $\left[\mathrm{Fe}(\mathrm{bpy})_{3}\right]^{2+}$, a transition metal model compound.
\end{abstract}

Keywords: time-resolved X-ray studies; XANES; EXAFS; X-ray diffraction; wide-angle X-ray scattering; RIXS; XRR

\section{Introduction}

Time-resolved chemical dynamics experiments exploiting hard X-radiation have become a mainstream option over the past 20 years, and also part of the vast field of Femtochemistry [1]. This application was driven by the desire to add new observables to the portfolio of otherwise optical laser-based techniques, which can offer additional information about the electronic and molecular 
structural changes during the course of a chemical reaction. Early proof-of-principle studies used intense synchrotron radiation (SR) [2-4] as well as laser-driven plasma sources [5] for this purpose. While the X-ray plasma sources offered superior picosecond and even sub-picosecond time resolution at the expense of flux, the synchrotron studies improved their signal to noise ratios, but remained limited to around 50-100 ps. Therefore, X-ray absorption spectroscopy (XAS) including X-ray absorption near-edge structure (XANES) and extended X-ray absorption fine structure (EXAFS) investigations were far from being able to study structural wavepacket dynamics, but were already able to investigate short-lived reaction intermediates with lifetimes well below $1 \mathrm{~ns}[2,4,6,7]$.

The improving signal quality of these time-resolved $X$-ray experiments triggered new studies towards improved modeling and theoretical interpretation of the measurements. This was performed for both time-resolved XANES and EXAFS studies [8-11], while in parallel the structural interpretation of related time-resolved wide-angle X-ray scattering (WAXS) results [12-15] improved considerably. This allowed for comparison of both complementary structural tools on the same time-resolved experiment, where van der Veen et al. [6] analyzed the recorded time-resolved EXAFS of a photoexcited Pt-POP compound, while M. Christensen et al. [12] analyzed the pump-probe WAXS signals from the same molecule, yielding nearly identical results. In view of the difficulty to model the excited state structures in an unambiguous fashion, it is highly attractive to employ complementary structural tools for the same sample and experiment $[10,16,17]$. This also marks the strategy of the FXE instrument design at European XFEL: to enable complementary structural dynamics tools quasi-simultaneously.

X-ray emission spectroscopy (XES) studies with 100 ps temporal resolution on photoexcited molecules in the solution phase were introduced by Vankó and colleagues at the Swiss Light Source [18], and were soon extended towards the first resonant inelastic X-ray scattering study with 100 ps time resolution [19]. This move opened the path for introducing more advanced $X$-ray spectroscopic techniques into the time domain with SR, and meanwhile $\mathrm{K} \alpha, \mathrm{K} \beta$ and even valence-to-core XES studies were successful $[10,11,20,21]$. One new ingredient delivered by XES is the spin sensitivity around transition metal (TM) ions in photoactive TM complexes, and this property is now being used to unravel the intermediate (spin) states in the excited state manifold [22-24], which are extremely difficult to obtain with optical tools on the subnanosecond time scales.

It also quickly became clear that studying photoexcited solutes using XES and WAXS (or solution scattering) in the same experiment can provide a deeper understanding of the interplay between structural and electronic structural dynamics. This was then demonstrated with SR $[10,16]$ and XFEL [24-27] radiation in benchmarking studies, and today most hard X-ray FEL sources do include XES capabilities next to forward scattering, underlining the important steps undertaken in the past to open this new technological tool for structural dynamics studies with femtosecond time resolution.

Below we present one result of this development in the scientific instrument FXE, which makes use of these complementary X-ray tools for chemistry applications. Located at the so called SASE1 undulator of European XFEL, FXE exploits the unprecedented X-ray flux available, which can deliver up to two orders of magnitude more photon flux than other XFEL facilities. This leap in X-ray power should also open up new methods in structural dynamics investigations, now enabling flux-hungry tools like X-ray Raman spectroscopy. But the high X-ray photon energy of up to $25 \mathrm{keV}$ in the fundamental lasing radiation will also allow exploiting WAXS tools on solvated chromophores, which will deliver more precise structural information about the photoexcited dynamic structures compared to the existing benchmark studies [28-31].

\section{Scientific Instrument FXE for Chemical Dynamics Studies}

\subsection{From the Undulator Exit to the Experimental Hall}

European XFEL is a user research laboratory located in the western part of the Hamburg metropolitan area, reaching from the DESY campus in Hamburg Bahrenfeld to the town of Schenefeld in Schleswig-Holstein. The initially three undulator sources provide intense flashes of tunable 
$\mathrm{X}$-radiation from the carbon $\mathrm{K}$ edge to very hard X-rays, or $250 \mathrm{eV}$ to $25 \mathrm{keV}$ in the fundamental lasing photon energy [32]. The X-radiation is delivered in bursts (or trains) of up to 2700 pulses every $100 \mathrm{~ms}$ (and each pulse in this burst spaced by $220 \mathrm{~ns}$ at $4.5 \mathrm{MHz}$ ), and can thus deliver up to 27,000 pulses every second. While the machine performance is still being ramped up, $2 \mathrm{~mJ}$ single pulse energy were already achieved at $9.3 \mathrm{keV}$ photon energy, operating presently at up to $8 \mathrm{~W}$ of radiation power, corresponding to an effective repetition rate of 4000 pulses/s.

The scientific instrument FXE (Femtosecond X-Ray Experiments) is located at the end of the SASE1 FEL undulator source (Figure 1). Two offset mirrors M1 and M2 allow rejection of high energy synchrotron radiation, and a third deflection mirror M3 guides the $X$-ray beam on a side-branch path into the FXE experimental area [32], while the straight path (with retracted M3) delivers X-rays into the neighboring scientific instrument SPB/SFX for single particle bio-imaging and serial femtosecond crystallography experiments [33].

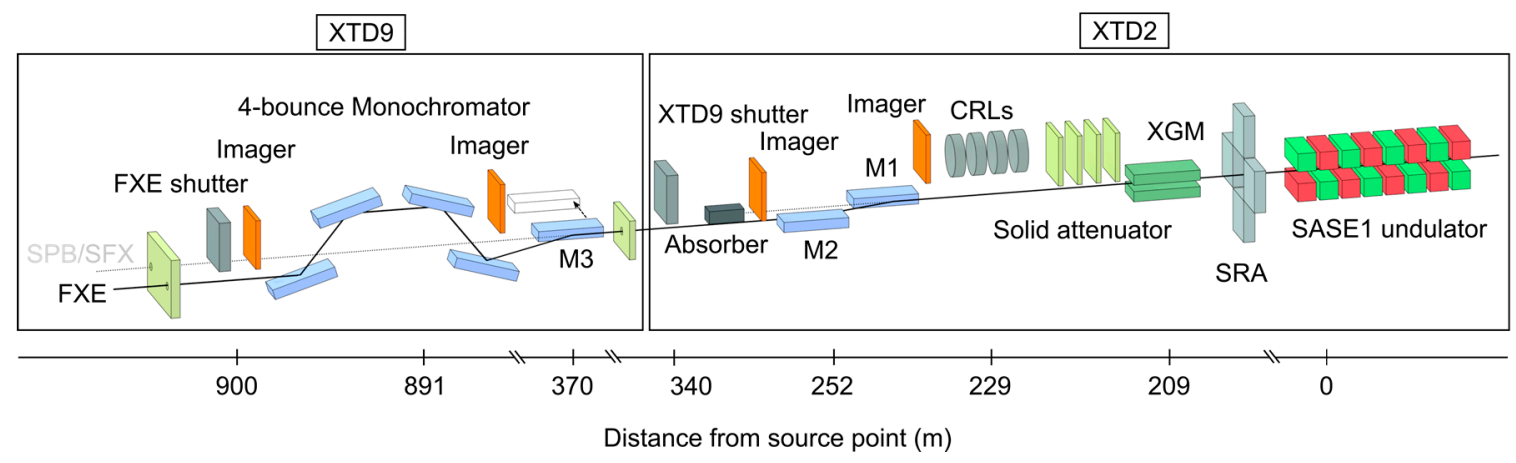

Figure 1. The $900 \mathrm{~m}$ long X-ray beam path in the photon transport tunnel sections (XTD2 and XTD9) from the SASE1 undulator exit (at the right) to the experimental hall (left end). The spontaneous radiation aperture (SRA) defines the FEL beam path. The beam is collimated by CRLs to an X-ray energy dependent beam size of about $1 \mathrm{~mm}$. Beam imagers and a gas-based intensity position monitor (XGM) measure the beam profile, intensity and location. A set of three X-ray mirrors (M1, M2 and M3) reject the background radiation and bring the beam into the FXE experimental hutch [32].

The XFEL radiation for FXE is collimated by a collection of compound refractive beryllium lenses (CRLs in Figure 1) to a beam size of around $1 \mathrm{~mm}$ diameter (for all energies in the 5-20 keV range) $230 \mathrm{~m}$ from the undulator exit or $670 \mathrm{~m}$ from the experimental hutch. Shortly before the beam enters the experimental hutch it passes through a (retractable) 4-bounce $\mathrm{Si}(111)$ primary monochromator $\left(\Delta \mathrm{E} / \mathrm{E}=10^{-5}-10^{-4}\right)$, which preserves the same beam path for both pink and monochromatic beams. This property thus allows us maintain the same X-ray spot on the sample in either operation mode, and thus requires no further spatial overlap search when switching from pink to monochromatic beams. While the $\mathrm{X}$-ray pulse arrival time will change between both modes, this arrival time change can be calculated and thus corrected for with the laser beam (more details below).

\subsection{FXE Instrumentation and Capabilities}

The X-ray beam entering the FXE experimental hutch (Figure 2) passes through an $8 \mathrm{~m}$ long optical branch, which is used for beam characterization (pulse energy, wavelength and location) and for focusing the beam onto the sample position. The sample interaction region is located on the top of a 10-axis motorized sample manipulation tower and surrounded by $2 \mathrm{X}$-ray emission spectrometers: (1) the wavelength-dispersive single-shot von Hamos spectrometer equipped with 16 cylindrically bent analyzer crystals of $0.5 \mathrm{~m}$ radius of curvature; and (2) the scanning Johann-type spectrometer with 5 spherically bend crystals of $1 \mathrm{~m}$ radius [34]. In the forward beam direction behind the sample interaction region the Large Pixel Detector (LPD) [35] is installed on a motorized granite support. The 3-parallel gain detector is capable of $4.5 \mathrm{MHz}$ framerate within the $10 \mathrm{~Hz}$ burst-mode and serves as the main WAXS detector. While the relatively thick sensor $(0.5 \mathrm{~mm} \mathrm{Si})$, provides good efficiency to photons 
with high energies of up to $25 \mathrm{keV}$, the large active area of circa $50 \mathrm{~cm}^{2}$ allows coverage of a wide region of reciprocal space (i.e., extended $q$-range). Additionally, two Jungfrau detectors [36], one single module 500k and another 2-module (1 Megapixel), can be mounted on a motorized robot arm above the sample area and utilized for measuring the X-ray emission spectra or X-ray scattering/diffraction from the sample if required. For fully pulse-resolved detection of the emission spectra at $\mathrm{MHz}$ pulse repetition rates, the robot can also be equipped with a one-dimensional Gotthard-I strip detector [37] (version II will also soon be available [38]).

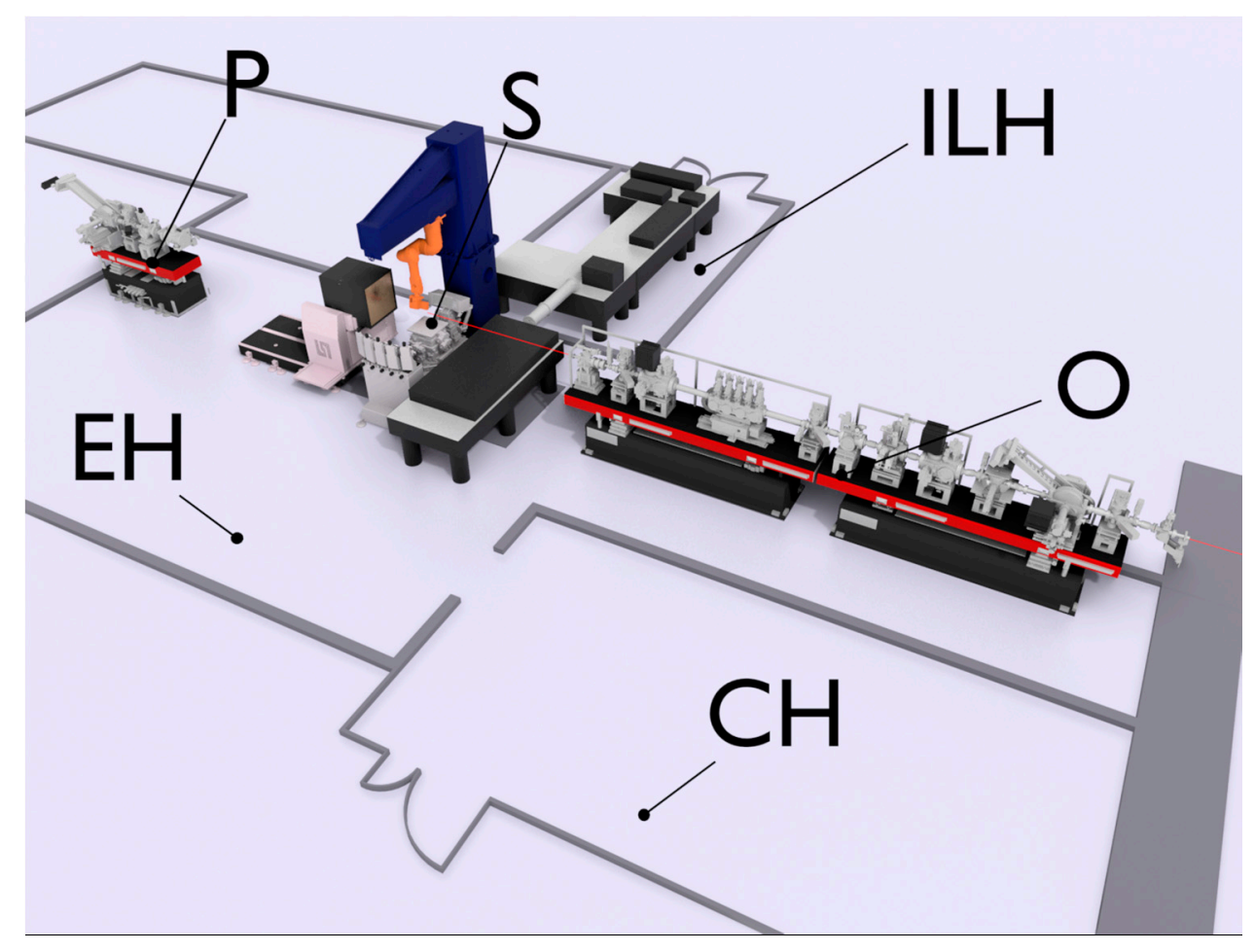

Figure 2. Layout of the scientific instrument FXE in the experimental hall of European XFEL. The SASE $\mathrm{X}$-ray beam enters the experimental hutch from the right and first passes the optics and diagnostics branch $(\mathrm{O})$ inside the experimental hutch $(\mathrm{EH})$ [34]. The beam is focused in the sample interaction region (S) and can optionally be transported through the LPD central hole to the post-diagnostics table (P) hosting beam imaging, spectral diagnostics and intensity-position monitor units. The optical laser radiation, the excitation source for the pump-probe experiments, is conditioned and characterized in a separate instrument laser hutch (ILH), the entire experiment is remotely conducted from the control hutch $(\mathrm{CH})$.

\subsection{The Pump Laser System and Synchronization}

Chemical reactions in solution phase are triggered by femtosecond laser radiation provided by a specially developed burst-mode femtosecond laser system, the Pump-Probe Laser (PPL) [39]. The system consists of an amplified slab laser producing $800 \mathrm{fs}$ long pulses with $1030 \mathrm{~nm}$ wavelength and a non-collinear optical parametric amplifier (NOPA) to generate broadband laser pulses centered at $800 \mathrm{~nm}$, which are routinely compressed down to $15 \mathrm{fs}$ pulse duration. Consequently, a very robust and dispersion controlled beam propagation setup is installed for making the shortest possible pulses available at the experiment interaction point. The $800 \mathrm{~nm}$ radiation can be subsequently frequency-converted to the second $(400 \mathrm{~nm})$ or third $(267 \mathrm{~nm})$ harmonics. Further tunability of the excitation wavelength will be provided via using a TOPAS system currently under installation and commissioning. The PPL system is synchronized to the XFEL machine using both the RF electronic reference signal and an optical fiber-based synchronization scheme, and the resulting arrival time jitter was measured at the sample position using an interferometric timing-tool scheme [34]. As a result, 
the RF synchronization scheme delivers a coarse timing accuracy with a remaining 250-300 fs FWHM jitter. This accuracy is significantly increased using the optical synchronization scheme, yielding a residual timing jitter of about $70 \mathrm{fs}$ FWHM.

\section{Chemistry Applications under Ambient Conditions}

Chemical Dynamics on electronically excited state potentials have been largely investigated with the advent of ultrafast laser-optical spectroscopy [40-42]. The dynamic shape of these potentials governs the molecular structure changes, reaction rate and outcome. Therefore, it is highly desired to have tools at hand, which allow us to determine the potential surface shape, especially at the so called conical intersections, where potential energy surfaces cross through each other, which determines the fate or final product state of the ongoing reaction. At these conical intersections adiabatic effects govern the transition probability $[43,44]$.

Over the past few years development of hard X-ray free-electron lasers enabled extending the well-established experimental optical pump/X-ray probe methodologies into the femtosecond time domain. The field of ultrafast photochemistry in solution has witnessed a number of benchmark studies taking full advantage of the direct chemical sensitivity offered by hard X-ray absorption and emission spectroscopies as well as X-ray scattering. The femtosecond resolution at XFELs allowed for element-specific spectroscopic investigations of transient processes and intermediate short-lived states in $3 \mathrm{~d}$ transition metal complexes.

In addition to identifying electronic relaxation pathways towards the lowest laying high spin excited state in prototypical spin-crossover systems [22-24] and charge transfer complexes [25], vibrational wavepackets were recently observed in Fe-carbene compounds using combined XES and WAXS tools [27]. Hereby transient molecular bond formation [30,45] and vibrational dynamics [29,31] were observed together with ultrafast molecular environment rearrangements in the immediate solvation shell [28], indicating the ability to also include intermolecular dynamic processes. At the same time, femtosecond XAS tools have been utilized for various $3 \mathrm{~d}$ metal complexes as a combined local and selective probe to deliver detailed information on the coupled electronic and structural changes throughout ultrafast photochemical processes [46,47], including nuclear wavepacket dynamics [48,49].

At the FXE station of European XFEL, the primary idea behind the design of the instrument lies in combining the X-ray structural spectroscopic and scattering methodologies into one experiment [34]. Considering the high photon energy capabilities of the European XFEL machine and FXE's flexible setup, the instrument enables vast possibilities for femtosecond X-ray absorption and non-resonant emission spectroscopies on a wide range of complexes containing elements from vanadium to molybdenum (K-edges) and from iodine to elements with the highest atomic numbers (L-edges). Additionally, the use of X-ray photon energies above those typically accessible at other FEL sources allows us to extend the range of momentum transfer covered in solution WAXS experiments, thus simultaneously providing high spatial resolution for monitoring structural changes in the solute, the thermodynamic state of the bulk solvent [50] as well as independently delivering information on solvent-shell molecular rearrangements [51], i.e., the solvation dynamics.

\subsection{Femtosecond X-ray Emission Capabilities}

The Johann-type and the von Hamos X-ray emission spectrometers of the FXE instrument can be operated simultaneously. Due to naturally higher solid angle coverage per unit of the emission energy, the scanning Johann spectrometer is more suited for applications with low signal yield (e.g., extremely low concentration, valence-to-core emission or X-ray Raman spectroscopy) or when high energy resolution is required in resonant inelastic X-ray scattering (RIXS) or high energy-resolved fluorescence detection (HERFD) type of measurements. The von Hamos dispersive-type spectrometer is adequate for comparably strong emission signals as well as when simultaneous coverage of multiple emission lines from one or several elements is required. Since the von Hamos spectrometer is operated with a single-module Jungfrau 500k detector with circa $38 \times 76 \mathrm{~cm}^{2}$ active area, loading the 16 -crystall $4 \times 4$ 
array with different cylindrical analyzers (compatible in terms of the Bragg angle) makes it possible to concurrently measure several emission lines. Such an arrangement brings the advantage of intrinsically correlated and normalized spectra in each detector image and also removing the jitter- and drift-related uncertainty of the laser and X-ray relative pulse arrival time.

As the proof-of-principle for femtosecond XES measurements at FXE, we studied photoexcited aqueous $\left[\mathrm{Fe}(\mathrm{bpy})_{3}\right]^{2+}$ (concentration $15 \mathrm{mM}$ ). This molecular model system represents a prototypical example of an iron spin transition complex and has been extensively studied in the past both at synchrotrons $[4,16,18,19,51]$ and XFELs $[22,24,26,45,47]$. The photochemical dynamics of $\left[\mathrm{Fe}(\mathrm{bpy})_{3}\right]^{2+}$ are well known and comprise major electronic and structural changes spanning timescales from tens of femtoseconds to several nanoseconds. In short, upon visible light excitation into the manifold of the metal-to-ligand charge-transfer states $\left({ }^{1,3} \mathrm{MLCT}\right)$ the complex relaxes to the lowest excited high spin state (quintet, spin $S=2$ ) via intermediate spin states (triplet, spin $S=1$ ) within a few hundreds of femtoseconds. The typical lifetime of the high spin quintet state in room temperature water solution is about 660 ps. Due to the population of anti-bonding $3 \mathrm{~d}$ molecular orbitals in the triplet and quintet metal centered states, the complex undergoes dramatic structural changes which elongate the Fe to ligand bond distance by about $0.1 \AA$ and $0.2 \AA$ in the triplet and quintet states, respectively. This structural change makes both time-resolved K-line XES $[18,19,22]$ and WAXS $[24,26,51]$ techniques very sensitive to these intermediate steps towards the quintet state.

In the XES experiment at FXE, the solution was excited by femtosecond pulses (50 fs FWHM duration) of $400 \mathrm{~nm}$ light and probed by X-ray pulses at $9.3 \mathrm{keV}$. Both the laser and the X-ray pulses had a $564 \mathrm{kHz}$ intra-train repetition rate (135 pulses/train) and pulse energies of $2 \mu \mathrm{J}$ and $1.4 \mathrm{~mJ}$ correspondingly. The X-ray trains arrived with a frequency of $10 \mathrm{~Hz}$, while the laser trains were adjusted to a $5 \mathrm{~Hz}$ delivery rate, thus subsequent $\mathrm{X}$-ray trains probed the sample at alternating laser ON ("pumped") and laser OFF ("unpumped") conditions. The solution was flowed in a $100 \mu \mathrm{m}$ round jet with a constant speed of about $60 \mathrm{~m} / \mathrm{s}$. Given the X-ray and the laser round spots of $10 \mu \mathrm{m}$ and 70 $\mu \mathrm{m}$ (FWHM diameters), respectively, and the intra-train repetition rate of this experiment at $564 \mathrm{kHz}$, the solution was refreshed for each pump-probe event, which was additionally visually confirmed using a triggered sample microscope.

The iron $K \alpha$ and $K \beta$ emission lines were simultaneously recorded on a Jungfrau 500k detector for several pump-probe delays (each delay point with about $30 \mathrm{~s}$ exposure); a typical detector image is shown in Figure 3A. The emission spectra were obtained by integrating a 4-pixel wide region-of-interest around the image maximum and then corrected for elastic scattering by the average of two background regions below and above the signal region of interest. The pixel-to-energy calibration was done by fitting the recorded spectra to calibrated reference data of the same compound. All spectra were normalized to their total area and then averaged. Differences were obtained by subtracting the spectra without laser excitation ("unpumped") from the spectra with laser excitation ("pumped"), and accumulated for each pump-probe delay, as presented in Figure 3B,C for the $K \alpha$ and $K \beta$ spectra, respectively.

To extract the kinetic traces as a function of pump-probe time delay around time-zero (Figure 4), the absolute difference XES spectra were integrated along regions-of-interest (marked by the green horizontal bars at the top of Figure 3B,C). The error bars were calculated using the standard error propagation from the errors of the mean spectra in the data sets for the excited and non-excited solution. The resulting time traces were fitted by an exponential function convoluted with a Gaussian-shaped instrument response function (IRF) and a constraining Heaviside function around time-zero via

$$
f\left(A, \sigma, t_{0}, \tau\right)=A \int_{-\infty}^{\infty} \frac{1}{\sigma \sqrt{2 \pi}} e^{-y^{2} / 2 \sigma^{2}} \mathrm{H}\left(t-t_{0}-y\right)\left(1-e^{-\left(t-t_{0}-y\right) / \tau}\right) d y
$$

using the position of time-zero $t_{0}$, the single-exponential rise-time $\tau$, the IRF width $\sigma$ and the signal amplitude $A$ as fit parameters. Due to naturally much higher signal-to-noise ratio in the K $\alpha$ measurement and because the $\mathrm{K} \beta$ traces were acquired truly simultaneously, the IRF width was first fitted for the $K \alpha$ data and this value used as fixed input for the $K \beta$ fitting routine while $t_{0}, \tau$ and $A$ 
remained free fit parameters in both fits. The fitted IRF FWHM yields $113 \pm 31$ fs for the K $\alpha$ data (used as input for $\mathrm{K} \beta$ ), and the fitted time-zero, $t_{0}$, delivered identical values for both emission lines (within the fit uncertainty of $14 \mathrm{fs}$ ). The extracted value for the IRF width lies within the expected ranges for the duration of the pump and probe pulses (each $50 \mathrm{fs}$ FWHM), the expected laser and the X-ray relative pulse arrival time jitter (here: about $70 \mathrm{fs}$ FWHM [34]) and the thickness of the cylindrical solution jet (thus up to $100 \mu \mathrm{m}$ thickness in transmission), leading to a smearing of the temporal response due to the group velocity mismatch for laser and X-rays (here about $1.1 \mathrm{fs} / \mu \mathrm{m}$ or $110 \mathrm{fs}$ total temporal walk-off), we estimated $140 \mathrm{fs}$ FWHM as an upper bound for the IRF, in agreement with the fit result of 113(31) fs.
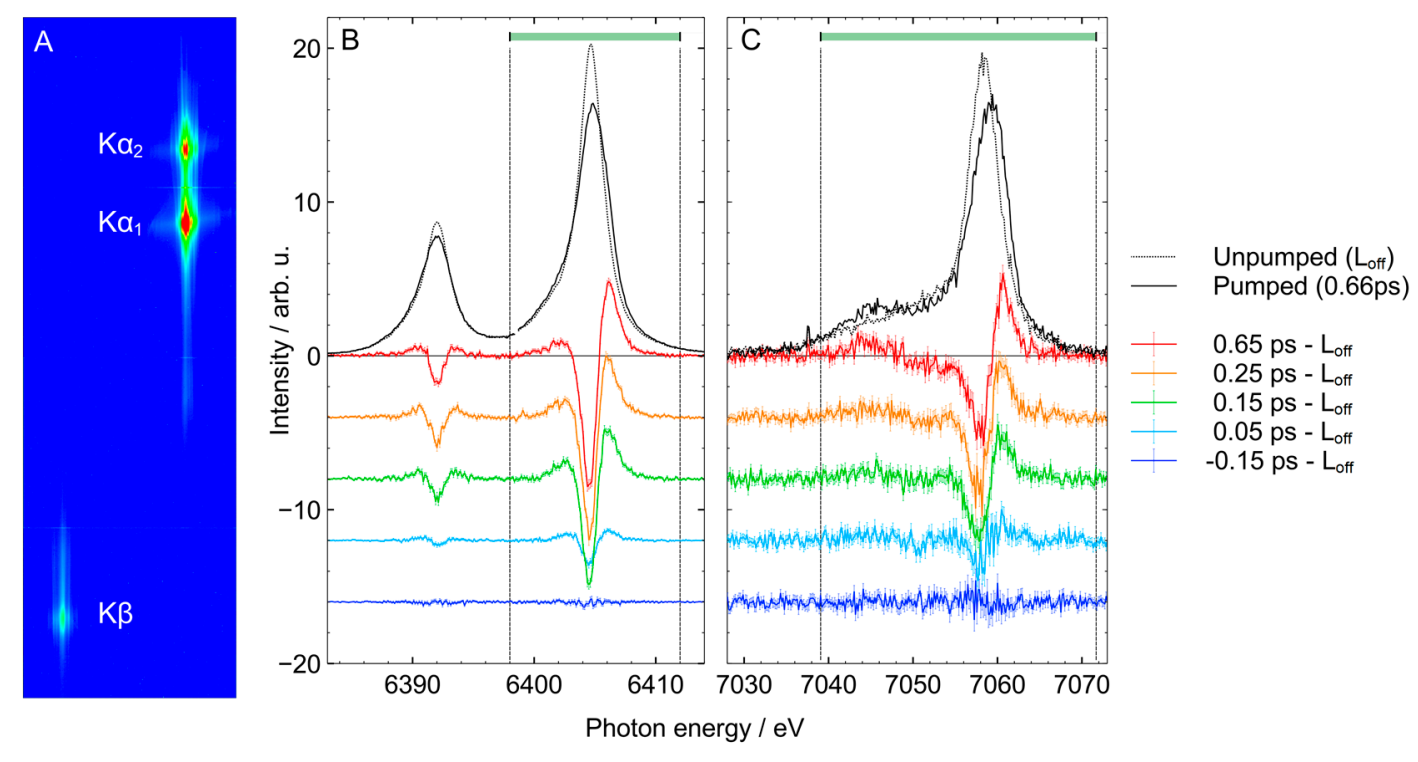

Figure 3. (A) Simultaneous measurement of $\mathrm{Fe} K \alpha$ and $\mathrm{K} \beta$ emission spectra on a Jungfrau $500 \mathrm{k}$ detector (only the exposed half of the detector active area is shown, blue and red colors correspond to low and high intensity signals, respectively); the extracted iron $K \alpha(\mathbf{B})$ and $K \beta(\mathbf{C})$ spectra and the respective difference traces for a set of selected pump-probe time delays. The "Unpumped" and "Pumped" curves correspond to emission spectra without (laser OFF) and with (laser ON) laser excitation, respectively. The $\mathrm{K} \alpha$ difference traces are multiplied by a factor of 2 for better visibility. The error bars on the plots correspond to one standard deviation of the mean for the respective datasets. The green horizontal bars above the spectra in (B) and (C) denote the region used for (squared) integration to generate the data points in Figure 4.

Following this basic analysis, it is evident that the rise time kinetics of the $K \alpha$ and $K \beta$ lines are not fully identical (Figure 4), which hints to the fact that each emission line has a different relative sensitivity with respect to the initially excited MLCT, intermediate triplet and the final high spin (quintet) states of this iron complex. This as a consequence yields different rise times for the extracted $\mathrm{K} \alpha$ and $\mathrm{K} \beta$ line traces, extending a similar observation within different regions of the $\mathrm{K} \beta$ emission spectrum alone [22]. It is nevertheless evident that even without a dedicated timing jitter correction the temporal resolution of pump-probe experiments at FXE is sufficient to resolve fastest intermediate states with lifetimes down to $150 \mathrm{fs}$, and e.g. the longer rise time of about $215 \mathrm{fs}$ (Figure 4) most likely originates from the intrinsic dynamic processes within the molecule in agreement with previous studies $[22,24,47]$. 


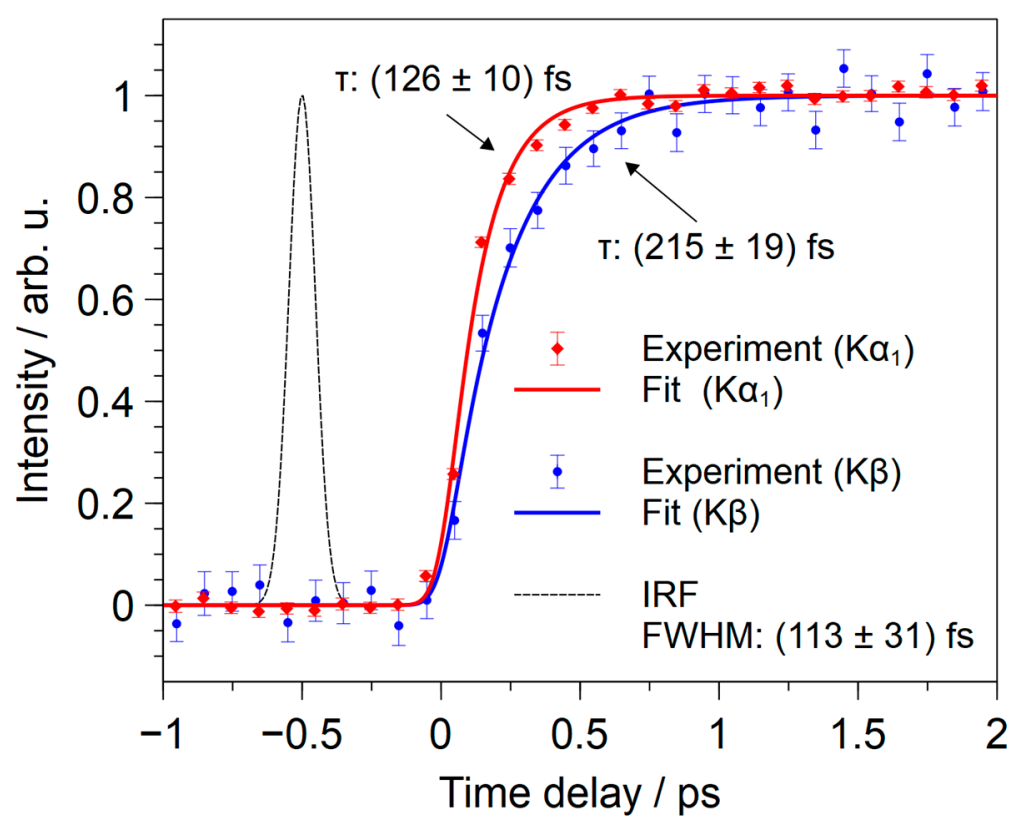

Figure 4. The kinetic traces as extracted from the difference $\mathrm{Fe} K \alpha$ and $\mathrm{K} \beta$ spectra calculated as integral of the absolute differences in the energy regions indicated by the dashed lines in Figure 3B,C respectively. The dashed black curve represents the Gaussian instrument response functions as extracted from the fit to the $\mathrm{K} \alpha$ data points (which is then propagated over the entire time delay in the convolution integral). The error bars on the plots correspond to one standard error directly propagated via sum of square errors of the difference traces in Figure 3B,C.

\subsection{Femtosecond Forward Scattering Capabilities}

X-ray solution scattering in WAXS configuration at FXE are performed using a LPD 1 Megapixel 4.5 $\mathrm{MHz}$ framerate detector [35] that has relatively high detection efficiency of up $20 \mathrm{keV}$ X-ray photon energies, which represents currently the highest available photon energy at the FXE instrument. First pump-probe WAXS measurements with the LPD were performed similar to the initial femtosecond XES experiments described above. Aqueous $\left[\mathrm{Fe}(\mathrm{bpy})_{3}\right]^{2+}$ (concentration $15 \mathrm{mM}$ ) was supplied by a round jet and excited by $400 \mathrm{~nm}$ pulses, as in the XES measurements. The X-ray photon energy was set to $12 \mathrm{keV}$ with 90 pulses per train at $564 \mathrm{kHz}$ intra-train repetition rate. Again, for every second X-ray train (thus at $5 \mathrm{~Hz}$ ) 90 synchronized laser pulses (and each pulse separated at the $564 \mathrm{kHz}$ pulse delivery rate) excited the sample that was probed by $90 \mathrm{X}$-ray pulses per train. Since the X-ray trains are delivered at a $10 \mathrm{~Hz}$ rate, we also record the reactant (non-illuminated) sample with this scheme at a $5 \mathrm{~Hz}$ train repetition rate as with the pump-probe signal itself. An X-ray pulse energy of about $170 \mu \mathrm{J}$ on sample was used for the WAXS measurements to avoid saturation of the high gain stage of the LPD, where the detector approaches its non-linear detection region.

The solution scattering image as detected by the LPD (Figure 5 left) and the respective azimuthally integrated difference curves (Figure 5 right) at three selected time delays show the influence of the solution excited by the laser pulse. Each delay step was collected in a 5 min scattering measurement. The difference resulting curves were fitted according to the standard methodology [12-15] using a linear combination fit (LCF) of three major contributions: the solute (molecule) term, the solute-solvent cage term and the (bulk) solvent changes via

$$
\Delta S(q, t)=\Delta S_{\text {solute }}(q, t)+\Delta S_{\text {cage }}(q, t)+\Delta S_{\text {solvent }}(q, t)
$$


where the solute and the cage terms can be calculated by the Debye formula and from the radial pair distribution functions $\left(g_{n m}(r)\right)$ for all $(\mathrm{n}, \mathrm{m})$ pairs of different atoms in the system:

$$
\Delta S_{\text {solute } / \text { cage }}(q)=\sum_{n} \sum_{m \neq n}\left(\frac{N_{n} N_{m}}{V} f_{n}(q) \cdot f_{m}(q) \int_{0}^{\infty} \Delta g_{n m}(r) \cdot \frac{\sin (q \cdot r)}{q \cdot r} 4 \pi r^{2} d r\right)
$$
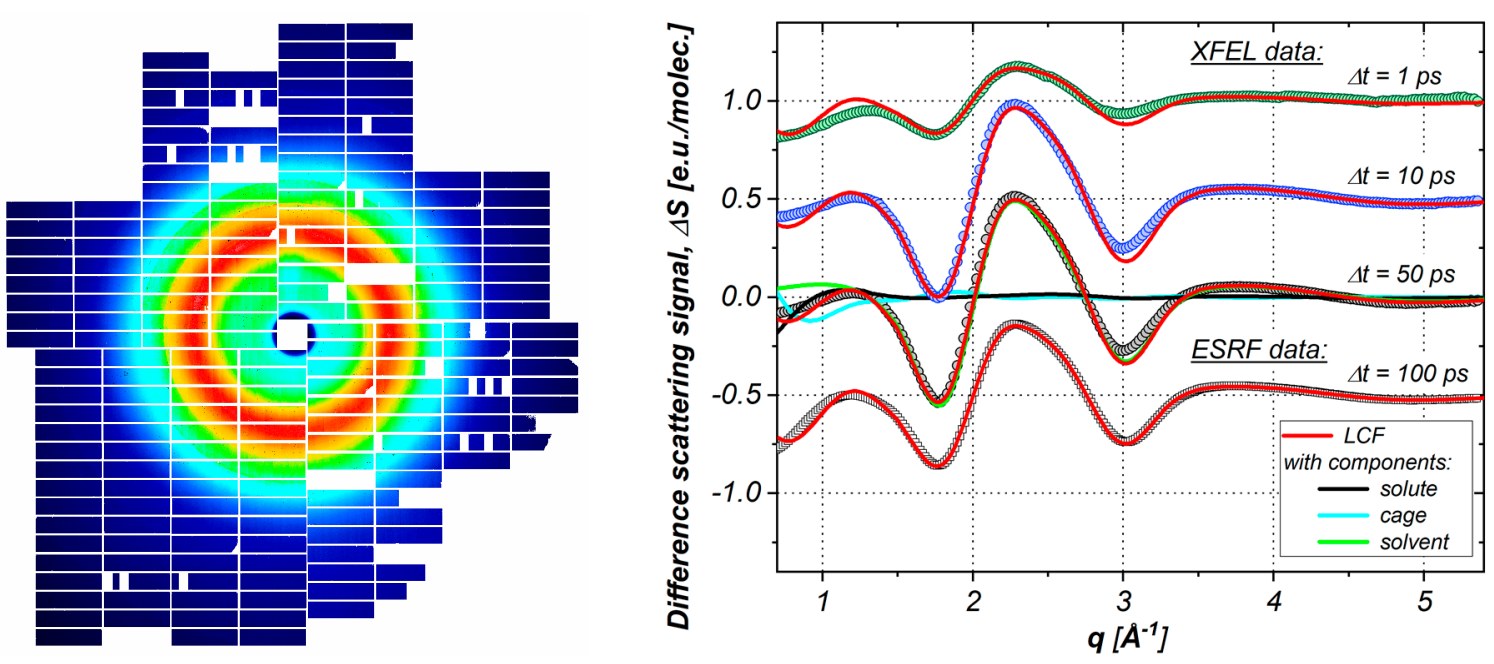

Figure 5. Left: average LPD image (200 shots) of WAXS from an aqueous solution of $\left[\mathrm{Fe}(\mathrm{bpy})_{3}\right]^{2+}$ collected with $12 \mathrm{keV}$ X-ray photons. Right: difference scattering curves measured in a pump-probe experiment at FXE (top 3 traces) and ESRF (the bottom trace, scaled by factor of 3) shifted vertically for clarity and the respective linear combination fits of the scattering data (red curves).

The solvent response $\Delta S_{\text {solvent }}(q, t)$ provides information on the thermodynamic parameters of the solvent bulk and contains contributions related to the solvent heating (transient temperature increase, $\Delta T(t))$ and thermal expansion (bulk density change, $\Delta \rho(t)$ ).

$$
\Delta S_{\text {solvent }}(q, t)=\left.\Delta T(t) \cdot \frac{\partial S(q)}{\partial T}\right|_{V=\text { const }}+\left.\Delta \rho(t) \cdot \frac{\partial S(q)}{\partial \rho}\right|_{T=\text { const }}
$$

where the derivatives $\left.\frac{\partial S(q)}{\partial T}\right|_{V=c o n s t}$ and $\left.\frac{\partial S(q)}{\partial \rho}\right|_{T=\text { const }}$ are determined by a separate calibration measurement [52] and the thermal expansion term is only relevant on the long nanosecond timescales [12-15].

For the results presented here, the photoinduced structural changes in the solute and its solvation shell (the cage term) were taken from the AIMD simulation results [53], while the solvent (water) response to impulsive heating was extracted from literature [51]. The FXE results in Figure 5 are compared to results from ESRF showing an appreciable agreement especially for the later time delays (10 ps and $50 \mathrm{ps})$, when the final high spin state in $\left[\mathrm{Fe}(\mathrm{bpy})_{3}\right]^{2+}$ has been fully formed in its thermally relaxed state together with the bulk solvent. For the shortest presented delay $\Delta t=1$ ps the LCF results yield the same excited state fraction for the high spin state $(\gamma=0.55)$ as for the later times, while the resulting bulk solvent temperature increase is about 3 times lower as compared to $\Delta \mathrm{t}=10 \mathrm{ps}$ $(\Delta \mathrm{T}(1 \mathrm{ps})=1.6 \mathrm{~K}$ versus $\Delta \mathrm{T}(10 \mathrm{ps})=4.6 \mathrm{~K})$, in agreement with expectations [24-29], since the bulk solvent temperature equilibrates on a several picoseconds time scale. Quantitatively the amount of the observed solvent temperature increase is large as compared to previously reported values $[24,26]$ for this system and may be related to the (sub)MHz repetition rate of the experiment and accumulated thermal excitation in the solvent, although the exact reason requires additional analysis and goes beyond the scope of the current work. 


\subsection{Potential for Enhanced Sensitivity and Resolution of WAXS}

One unique selling point for femtosecond solution WAXS at the FXE instrument lies in the high photon energies of up to $20 \mathrm{keV}$, which cannot yet be delivered as fundamental radiation at other FEL sources. Already in the Fall of 2019 the European XFEL machine has demonstrated stable lasing with $16.5 \mathrm{GeV}$ electrons resulting in $20 \mathrm{keV} X$-ray photons with up to $900 \mu \mathrm{J}$ energy per pulse in the FXE branch. With such high photon energies and the high energy detection capability of LPD, it is possible to considerably extend the range of recorded momentum transfer in the WAXS patterns. As an example, for $20 \mathrm{keV}$ with the large LPD detection area one can expect the maximum momentum transfer $\left(q_{\max }\right)$ up to $12 \AA^{-1}$. In this $q$-range, high resolution solute structural determination is possible together with a non-correlated extraction of the solvent observables, and all this during the very same measurement. This has been recently demonstrated in the proof-of-principle synchrotron pump-probe WAXS studies with $25.2 \mathrm{keV}$ photons and $100 \mathrm{ps}$ time resolution [50,51]. Figure 6 shows an example of such high-resolution scattering measurement on the aqueous $\left[\mathrm{Fe}(\mathrm{bpy})_{3}\right]^{2+}$ performed at the ESRF synchrotron. The extended $q$-range allows to distinguish very similar potential molecular structures (here, the AIMD-calculated structure and the ${ }^{5} \mathrm{~A}$ state structure in $\mathrm{D}_{3}$ symmetry from DFT calculations) as well as substantially reduces the correlation of the LCF parameters for the extracted solvent (here the solvent temperature rise $\Delta \mathrm{T}$ ) and the solute (here the excited state fraction) components.

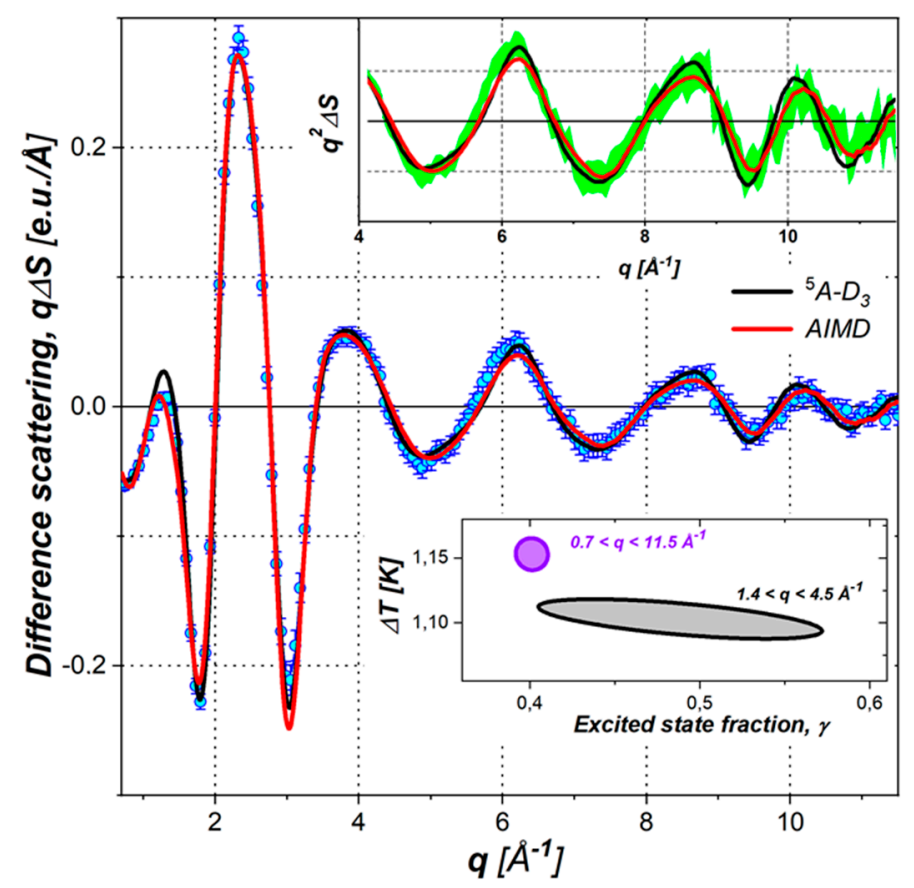

Figure 6. Pump-probe difference WAXS signal from an aqueous solution of $\left[\mathrm{Fe}(\mathrm{bpy})_{3}\right]^{2+}$ collected at the ESRF synchrotron with $25.2 \mathrm{keV}$ X-ray photons at 100 ps time delay. The experimental curve (cyan circles and green trace in the top inset) was fitted using a LCF and solute structure delivered by the AIMD (red curve) or DFT ( ${ }^{5} \mathrm{~S}_{-} \mathrm{D}_{3}$ state, black curve). The high spatial resolution enabled by the large $q$-range allows for selecting the best suited structural models of the solution (see top inset) and better decorrelation of the solute (excited state fraction) and the solvent (bulk temperature rise) observables as compared to the case of the limited $q$-range (see the bottom inset).

\subsection{Towards Femtosecond XANES and Advanced Spectroscopic Techniques}

Femtosecond XAS at FXE (similar to XES) is designed to be performed in two principal modes: scanning and single-shot. For the scanning configuration, FXE is equipped with a 4-bounce fixed-exit Si(111) monochromator based on 2 pairs of cryogenically cooled quasi channel-cut crystals. The detection of absorption spectra will be performed with fast PIN diode or APD (avalanche photodiode) 
point detectors, either in total fluorescence yield (TFY) mode, high energy-resolved fluorescence detection (HERFD) or transmission mode, depending on the geometry, sample concentration and chemical element (absorption cross section) of interest. By adjusting the FEL undulator gap synchronously with the monochromator energy setting the baseline capabilities of performing standard 20-50 eV XANES, spectroscopy at FXE is enhanced to the possibility of recording EXAFS over hundreds of $\mathrm{eV}$. The femtosecond time resolution can be preserved by adapting the laser time delay to the varying $\mathrm{X}$-ray pulse arrival times during such monochromator scans, which changes the $\mathrm{X}$-ray beam path length through the monochromator in a predictable way, i.e., continuously increasing the photon energy geometrically leads to shortening of the beam path through the 4 bounces due to the decreasing Bragg angle, thus shifting the X-ray pulse arrival to earlier times. Both X-ray absorption techniques are indispensable for probing the electronic and local structural dynamics during the course of ultrafast photochemical processes [45-48,54].

The single-shot $\mathrm{X}$-ray absorption configuration is based on two identical curved-crystal spectrum analyzers which are positioned upstream and downstream of the sample interaction region and equipped with one-dimensional Gotthard detectors to simultaneously measure the dispersed SASE spectra on a single-shot basis even at pulse arrival rates in the $\mathrm{MHz}$ range. Both spectrum analyzers have identical sets of two Si ((111) and (110) cuts), one Ge (110) and one $20 \mu \mathrm{m}$ thick diamond (111) bent crystals to cover different energy ranges with selected resolution and efficiency over the 5-20 keV range. Only the diamond crystals can be used non-invasively in the direct beam while the Si and Ge crystals are operated with the first order beam behind a transmissive diamond diffraction grating installed upstream in the tunnel part of the beamline. Such correlated single-shot measurements using both spectrum analyzers allow us to quickly accumulate X-ray absorption spectra with the "pink" SASE beam (up to $0.2 \%$ relative bandwidth) near the selected absorption edge $[55,56]$ within the entire $\mathrm{X}$-ray photon energy range covered by the instrument $(5-20 \mathrm{keV})$.

In addition to the information content due to the element-specific chemical sensitivity provided by X-ray absorption spectroscopies, the technique typically delivers strong difference signals, even for weak photoinduced changes in the electronic or molecular structure. This allows for a rapid optimization of the pump-probe experimental parameters, which include the spatiotemporal overlap of both beams on the sample, the optimal excitation fluence and wavelength, the relevant timescales, etc. In this respect using the full SASE bandwidth for the initial single-shot XAS measurements on a system is advantageous over the scanning method, as it allows us to conserve the X-ray beampath and thus the pump-probe time delay and overlap for the following simultaneous non-resonant XES and WAXS studies, within the same experiment.

\section{Conclusions}

The scientific instrument FXE of the European XFEL is dedicated to permitting ultrafast studies of photochemical dynamics in the solution phase, providing: (i) atomic-scale resolution on structures of the reacting solutes and their solvation shell; (ii) electronic spin- and oxidation state sensitive information; (iii) insight into the local coordination environment around photo-chemically active centers. Capabilities of the instrument include single-shot and scanning types of X-ray absorption and non-resonant emission spectroscopies combined with X-ray solution scattering to provide the complete set of probes for monitoring photochemical reactions with femtosecond temporal resolution currently down to about 115 fs FWHM before applying timing jitter correction in a standard liquid chemistry experiment.

Author Contributions: A.G., W.G. and C.B. created the conceptual and technical design of the scientific instrument FXE with contributions from D.K., F.A.L. and P.Z.; all authors aided in its commissioning including the first femtochemistry experiments, the results were reduced and analyzed by D.K. and F.O.; the article was drafted by C.B., D.K. and F.O. with input from all authors. All authors have read and agree to the published version of the manuscript. 
Funding: This work was funded by the European XFEL GmbH. We are thankful to the Deutsche Forschungsgemeinschaft (DFG) for support via the The Hamburg Centre of Ultrafast Imaging (CUI) and via the collaborative research initiative SFB925 (Teilprojekt A4) and to the Federal Ministry of Education and Research of Germany (05K16PE1). Portions of the work relating to liquid jets and timing tool strategies were funded by EUCALL/PUCCA (Horizon 2020, grant No. 654220).

Acknowledgments: The authors acknowledge technical support from various groups of the European XFEL $\mathrm{GmbH}$ including the Detector group, the Controls group, the Data Analysis group, the IT group, the Electronics groups, the Photon Diagnostics group, the Optics group and all others involved in the commission and operation of the XFEL facility.

Conflicts of Interest: The authors declare no conflict of interest.

\section{References}

1. Zewail, A.H. Femtochemistry: Atomic-Scale Dynamics of the Chemical Bond. J. Phys. Chem. A 2000, 104, 5660-5694. [CrossRef]

2. Chen, L.X.; Shaw, G.B.; Novozhilova, I.; Liu, T.; Jennings, G.; Attenkofer, K.; Meyer, G.J.; Coppens, P. MLCT State Structure and Dynamics of a Copper(I) Diimine Complex Characterized by Pump-Probe X-ray and Laser Spectroscopies and DFT Calculations. J. Am. Chem. Soc. 2003, 125, 7022-7034. [CrossRef]

3. Saes, M.; Bressler, C.; Abela, R.; Grolimund, D.; Johnson, S.L.; Heimann, P.A.; Chergui, M. Observing Photochemical Transients by Ultrafast X-ray Absorption Spectroscopy. Phys. Rev. Lett. 2003, 90, 047403. [CrossRef]

4. Gawelda, W.; Pham, V.-T.; Benfatto, M.; Zaushitsyn, Y.; Kaiser, M.; Grolimund, D.; Johnson, S.L.; Abela, R.; Hauser, A.; Bressler, C.; et al. Structural Determination of a Short-Lived Excited Iron(II) Complex by Picosecond X-Ray Absorption Spectroscopy. Phys. Rev. Lett. 2007, 98, 057401. [CrossRef]

5. Ráksi, F.; Wilson, K.R.; Jiang, Z.; Ikhlef, A.; Côté, C.Y.; Kieffer, J.-C. Ultrafast X-ray absorption probing of a chemical reaction. J. Chem. Phys. 1996, 104, 6066-6069. [CrossRef]

6. Van der Veen, R.M.; Milne, C.J.; El Nahhas, A.; Lima, F.A.; Pham, V.-T.; Best, J.; Weinstein, J.A.; Borca, C.N.; Abela, R.; Bressler, C.; et al. Structural Determination of a Photochemically Active Diplatinum Molecule by Time-Resolved EXAFS Spectroscopy. Angew. Chem. Int. Ed. 2009, 48, 2711-2714. [CrossRef]

7. Gawelda, W.; Johnson, M.; De Groot, F.M.F.; Abela, R.; Bressler, C.; Chergui, M. Electronic and molecular structure of photoexcited $\left[\mathrm{RuII}(\mathrm{bpy})_{3}\right]^{2+}$ probed by picosecond X-ray absorption spectroscopy. J. Am. Chem. Soc. 2006, 128, 5001-5009. [CrossRef]

8. Canton, S.E.; Zhang, X.; Lawson Daku, L.M.; Smeigh, A.L.; Zhang, J.; Liu, Y.; Wallentin, C.-J.; Attenkofer, K.; Jennings, G.; Kurtz, C.A.; et al. Probing the Anisotropic Distortion of Photoexcited Spin Crossover Complexes with Picosecond X-ray Absorption Spectroscopy. J. Phys. Chem. C 2014, 118, 4536-4545. [CrossRef]

9. Zhang, X.; Canton, S.E.; Smolentsev, G.; Wallentin, C.J.; Liu, Y.; Kong, Q.; Attenkofer, K.; Stickrath, A.B.; Mara, M.W.; Chen, L.X.; et al. Highly accurate excited-state structure of $\left[\mathrm{Os}(\mathrm{bpy})_{2} \mathrm{dcbpy}\right]^{2+}$ determined by X-ray transient absorption spectroscopy. J. Am. Chem. Soc. 2014, 136, 8804-8809. [CrossRef] [PubMed]

10. Vankó, G.; Bordage, A.; Pápai, M.; Haldrup, K.; Glatzel, P.; March, A.M.; Doumy, G.; Britz, A.; Galler, A.; Assefa, T.; et al. Detailed characterization of a nanosecond-lived excited state: X-ray and theoretical investigation of the quintet state in photoexcited $\left[\mathrm{Fe}(\mathrm{terpy})_{2}\right]^{2+}$. J. Phys. Chem. C Nanomater. Interfaces 2015, 119, 5888-5902. [CrossRef] [PubMed]

11. Britz, A.; Gawelda, W.; Assefa, T.A.; Jamula, L.L.; Yarranton, J.T.; Galler, A.; Khakhulin, D.; Diez, M.; Harder, M.; Doumy, G.; et al. Using Ultrafast X-ray Spectroscopy to Address Questions in Ligand-Field Theory: The Excited State Spin and Structure of [Fe(dcpp) $\left.{ }_{2}\right]^{2+}$. Inorg. Chem. 2019, 58, 9341-9350. [CrossRef]

12. Christensen, M.; Haldrup, K.; Bechgaard, K.; Feidenhans'l, R.; Kong, Q.; Cammarata, M.; Russo, M.L.; Wulff, M.; Harrit, N.; Nielsen, M.M. Time-Resolved X-ray Scattering of an Electronically Excited State in Solution. Structure of the ${ }^{3} \mathrm{~A}_{2 \mathrm{u}}$ State of Tetrakis- $\mu$-pyrophosphitodiplatinate(II). J. Am. Chem. Soc. 2009, 131, 502-508. [CrossRef]

13. Haldrup, K.; Harlang, T.; Christensen, M.; Dohn, A.; van Driel, T.B.; Kjær, K.S.; Harrit, N.; Vibenholt, J.; Guerin, L.; Wulff, M.; et al. Bond Shortening (1.4 $⿱$ A) in the Singlet and Triplet Excited States of $\left[\operatorname{Ir}_{2}(\operatorname{dimen})_{4}\right]^{2+}$ in Solution Determined by Time-Resolved X-ray Scattering. Inorg. Chem. 2011, 50, 9329-9336. [CrossRef] 
14. Kong, Q.; Lee, J.H.; Kim, K.H.; Kim, J.; Wulff, M.; Ihee, H.; Koch, M.H.J. Ultrafast X-ray Solution Scattering Reveals Different Reaction Pathways in the Photolysis of Triruthenium Dodecacarbonyl $\left(\mathrm{Ru}_{3}(\mathrm{CO})_{12}\right)$ after Ultraviolet and Visible Excitation. J. Am. Chem. Soc. 2010, 132, 2600-2607. [CrossRef]

15. Lee, J.H.; Wulff, M.; Bratos, S.; Petersen, J.; Guerin, L.; Leicknam, J.-C.; Cammarata, M.; Kong, Q.; Kim, J.; Møller, K.B.; et al. Filming the Birth of Molecules and Accompanying Solvent Rearrangement. J. Am. Chem. Soc. 2013, 135, 3255-3261. [CrossRef]

16. Haldrup, K.; Vankó, G.; Gawelda, W.; Galler, A.; Doumy, G.; March, A.M.; Kanter, E.P.; Bordage, A.; Dohn, A.; Van Driel, T.B.; et al. Guest-Host Interactions Investigated by Time-Resolved X-ray Spectroscopies and Scattering at $\mathrm{MHz}$ Rates: Solvation Dynamics and Photoinduced Spin Transition in Aqueous Fe(bipy) $3^{2+}$. J. Phys. Chem. A 2012, 116, 9878-9887. [CrossRef]

17. Naumova, M.; Khakhulin, D.; Rebarz, M.; Rohrmüller, M.; Dicke, B.; Biednov, M.; Britz, A.; Espinoza, S.; Grimm-Lebsanft, B.; Kloz, M.; et al. Structural dynamics upon photoexcitation-induced charge transfer in a dicopper(i)-disulfide complex. Phys. Chem. Chem. Phys. 2018, 20, 6274-6286. [CrossRef]

18. Vankó, G.; Glatzel, P.; Pham, V.-T.; Abela, R.; Grolimund, D.; Borca, C.N.; Johnson, S.L.; Milne, C.J.; Bressler, C. Picosecond Time-Resolved X-Ray Emission Spectroscopy: Ultrafast Spin-State Determination in an Iron Complex. Angew. Chem. Int. Ed. 2010, 49, 5910-5912. [CrossRef]

19. Vankó, G.; Bordage, A.; Glatzel, P.; Gallo, E.; Rovezzi, M.; Gawelda, W.; Galler, A.; Bressler, C.; Doumy, G.; March, A.M.; et al. Spin-state studies with XES and RIXS: From static to ultrafast. J. Electron Spectrosc. Relat. Phenom. 2013, 188, 166-171. [CrossRef]

20. March, A.M.; Assefa, T.A.; Boemer, C.; Bressler, C.; Britz, A.; Diez, M.; Doumy, G.; Galler, A.; Harder, M.; Khakhulin, D.; et al. Probing Transient Valence Orbital Changes with Picosecond Valence-to-Core X-ray Emission Spectroscopy. J. Phys. Chem. C 2017, 121, 2620-2626. [CrossRef]

21. Tu, M.F.; Doumy, G.; Al Haddad, A.; March, A.M.; Southworth, S.H.; Assoufid, L.; Kumagai, Y.; Walko, D.A.; Di Chiara, A.D.; Liu, Z.; et al. Micro-focused MHz pink beam for time-resolved X-ray emission spectroscopy. J. Synchrotron Radiat. 2019, 26, 1956-1966. [CrossRef]

22. Zhang, W.; Alonso-Mori, R.; Bergmann, U.; Bressler, C.; Chollet, M.; Galler, A.; Gawelda, W.; Hadt, R.G.; Hartsock, R.W.; Kroll, T.; et al. Tracking excited-state charge and spin dynamics in iron coordination complexes. Nature 2014, 509, 345-348. [CrossRef]

23. Zhang, W.; Kjær, K.S.; Alonso-Mori, R.; Bergmann, U.; Chollet, M.; Fredin, L.A.; Hadt, R.G.; Hartsock, R.W.; Harlang, T.; Kroll, T.; et al. Manipulating charge transfer excited state relaxation and spin crossover in iron coordination complexes with ligand substitution. Chem. Sci. 2017, 8, 515-523. [CrossRef]

24. Kjær, K.S.; Van Driel, T.B.; Harlang, T.C.B.; Kunnus, K.; Biasin, E.; Ledbetter, K.; Hartsock, R.W.; Reinhard, M.E.; Koroidov, S.; Li, L.; et al. Finding intersections between electronic excited state potential energy surfaces with simultaneous ultrafast X-ray scattering and spectroscopy. Chem. Sci. 2019, 10, 5749-5760. [CrossRef]

25. Canton, S.E.; Kjær, K.S.; Vankó, G.; van Driel, T.B.; Adachi, S.; Bordage, A.; Bressler, C.; Chabera, P.; Christensen, M.; Dohn, A.O.; et al. Visualizing the non-equilibrium dynamics of photoinduced intramolecular electron transfer with femtosecond X-ray pulses. Nat. Commun. 2015, 6, 6359. [CrossRef]

26. Haldrup, K.; Gawelda, W.; Abela, R.; Alonso-Mori, R.; Bergmann, U.; Bordage, A.; Cammarata, M.; Canton, S.E.; Dohn, A.O.; van Driel, T.B.; et al. Observing Solvation Dynamics with Simultaneous Femtosecond X-ray Emission Spectroscopy and X-ray Scattering. J. Phys. Chem. B 2016, 120, 1158-1168. [CrossRef]

27. Kunnus, K.; Vacher, M.; Harlang, T.C.B.; Kjær, K.S.; Haldrup, K.; Biasin, E.; van Driel, T.B.; Pápa, M.; Chabera, P.; Liu, Y.; et al. Vibrational wavepacket dynamics in Fe carbene photosensitizer determined with femtosecond X-ray emission and scattering. Nat. Commun. 2020, 11, 634. [CrossRef]

28. Van Driel, T.B.; Kjær, K.S.; Hartsock, R.W.; Dohn, A.O.; Harlang, T.; Chollet, M.; Christensen, M.; Gawelda, W.; Henriksen, N.E.; Kim, J.G.; et al. Atomistic characterization of the active-site solvation dynamics of a model photocatalyst. Nat. Commun. 2016, 7, 13678. [CrossRef]

29. Biasin, E.; van Driel, T.B.; Kjær, K.S.; Dohn, A.O.; Christensen, M.; Harlang, T.; Chabera, P.; Liu, Y.; Uhlig, J.; Pápai, M.; et al. Femtosecond X-ray Scattering Study of Ultrafast Photoinduced Structural Dynamics in Solvated $\left[\mathrm{Co}(\text { terpy })_{2}\right]^{2+}$. Phys. Rev. Lett. 2016, 117, 013002. [CrossRef]

30. Kim, K.H.; Kim, J.G.; Nozawa, S.; Sato, T.; Oang, K.Y.; Kim, T.W.; Ki, H.; Jo, J.; Park, S.; Song, C.; et al. Direct observation of bond formation in solution with femtosecond X-ray scattering. Nature 2015, 518, 385-389. [CrossRef] 
31. Haldrup, K.; Levi, G.; Biasin, E.; Vester, P.; Laursen, M.G.; Beyer, F.; Kjær, K.S.; Brandt van Driel, T.; Harlang, T.; Dohn, A.O.; et al. Ultrafast X-ray Scattering Measurements of Coherent Structural Dynamics on the Ground-State Potential Energy Surface of a Diplatinum Molecule. Phys. Rev. Lett. 2019, 122, 063001. [CrossRef] [PubMed]

32. Tschentscher, T.; Bressler, C.; Grünert, J.; Madsen, A.; Mancuso, A.; Meyer, M.; Scherz, A.; Sinn, H.; Zastrau, U. Photon Beam Transport and Scientific Instruments at the European XFEL. Appl. Sci. 2017, 7, 592. [CrossRef]

33. Mancuso, A.P.; Aquila, A.; Batchelor, L.; Bean, R.J.; Bielecki, J.; Borchers, G.; Doerner, K.; Giewekemeyer, K.; Graceffa, R.; Kelsey, O.D.; et al. The single particles, clusters and biomolecules and serial femtosecond crystallography instrument of the european XFEL: Initial installation. J. Synchrotron Radiat. 2019, 26, 660-676. [CrossRef]

34. Galler, A.; Gawelda, W.; Biednov, M.; Bomer, C.; Britz, A.; Brockhauser, S.; Choi, T.K.; Diez, M.; Frankenberger, P.; French, M.; et al. Scientific instrument Femtosecond X-ray Experiments (FXE): Instrumentation and baseline experimental capabilities. J. Synchrotron Radiat. 2019, 26, 1432-1447. [CrossRef] [PubMed]

35. Koch, A.; Hart, M.; Nicholls, T.; Angelsen, C.; Coughlan, J.; French, M.; Hauf, S.; Kuster, M.; Sztuk-Dambietz, J.; Turcato, M.; et al. Performance of an LPD prototype detector at MHz frame rates under Synchrotron and FEL radiation. J. Instrum. 2013, 8, C11001. [CrossRef]

36. Mozzanica, A.; Andrä, M.; Barten, R.; Bergamaschi, A.; Chiriotti, S.; Brückner, M.; Dinapoli, R.; Fröjdh, E.; Greiffenberg, D.; Leonarski, F.; et al. The JUNGFRAU Detector for Applications at Synchrotron Light Sources and XFELs. Synchrotron Radiat. News 2018, 31, 16-20. [CrossRef]

37. Mozzanica, A.; Bergamaschi, A.; Dinapoli, R.; Graafsma, H.; Greiffenberg, D.; Henrich, B.; Johnson, I.; Lohmann, M.; Valeria, R.; Schmitt, B.; et al. The GOTTHARD charge integrating readout detector: Design and characterization. J. Instrum. 2012, 7, C01019. [CrossRef]

38. Zhang, J.; Andrä, M.; Barten, R.; Bergamaschi, A.; Brückner, M.; Dinapoli, R.; Fröjdh, E.; Greiffenberg, D.; Lopez-Cuenca, C.; Mezza, D.; et al. Towards Gotthard-II: Development of a silicon microstrip detector for the European X-ray Free-Electron Laser. J. Instrum. 2018, 13, P01025. [CrossRef]

39. Palmer, G.; Kellert, M.; Wang, J.; Emons, M.; Wegner, U.; Kane, D.; Pallas, F.; Jezynski, T.; Venkatesan, S.; Rompotis, D.; et al. Pump-probe laser system at the FXE and SPB/SFX instruments of the European X-ray Free-Electron Laser Facility. J. Synchrotron Radiat. 2019, 26, 328-332. [CrossRef]

40. Zewail, A.H. Laser Femtochemistry. Science 1988, 242, 1645-1653. [CrossRef]

41. Scherer, N.F.; Jonas, D.M.; Fleming, G.R. Femtosecond wave packet and chemical reaction dynamics of iodine in solution: Tunable probe study of motion along the reaction coordinate. J. Chem. Phys. 1993, 99, 153-168. [CrossRef]

42. Monat, J.E.; McCusker, J.K. Femtosecond Excited-State Dynamics of an Iron(II) Polypyridyl Solar Cell Sensitizer Model. J. Am. Chem. Soc. 2000, 122, 4092-4097. [CrossRef]

43. Levine, B.G.; Martínez, T.J. Isomerization Through Conical Intersections. Annu. Rev. Phys. Chem. 2007, 58, 613-634. [CrossRef] [PubMed]

44. Martinez, T.J. Physical chemistry: Seaming is believing. Nature 2010, 467, 412-413. [CrossRef]

45. Kong, Q.Y.; Laursen, M.G.; Haldrup, K.; Kjær, K.S.; Khakhulin, D.; Biasin, E.; Van Driel, T.B.; Wulff, M.; Kabanova, V.; Vuilleumier, R.; et al. Initial metal-metal bond breakage detected by fs X-ray scattering in the photolysis of $\mathrm{Ru}_{3}(\mathrm{CO})_{12}$ in cyclohexane at $400 \mathrm{~nm}$. Photochem. Photobiol. Sci. 2019, 18, 319-327. [CrossRef]

46. Lemke, H.T.; Bressler, C.; Chen, L.X.; Fritz, D.M.; Gaffney, K.J.; Galler, A.; Gawelda, W.; Haldrup, K.; Hartsock, R.W.; Ihee, H.; et al. Femtosecond X-ray Absorption Spectroscopy at a Hard X-ray Free Electron Laser: Application to Spin Crossover Dynamics. J. Phys. Chem. A 2013, 117, 735-740. [CrossRef]

47. Shelby, M.L.; Lestrange, P.J.; Jackson, N.E.; Haldrup, K.; Mara, M.W.; Stickrath, A.B.; Zhu, D.; Lemke, H.T.; Chollet, M.; Hoffman, B.M.; et al. Ultrafast Excited State Relaxation of a Metalloporphyrin Revealed by Femtosecond X-ray Absorption Spectroscopy. J. Am. Chem. Soc. 2016, 138, 8752-8764. [CrossRef]

48. Lemke, H.T.; Kjær, K.S.; Hartsock, R.; van Driel, T.B.; Chollet, M.; Glownia, J.M.; Song, S.; Zhu, D.; Pace, E.; Matar, S.F.; et al. Coherent structural trapping through wave packet dispersion during photoinduced spin state switching. Nat. Commun. 2017, 8, 15342. [CrossRef]

49. Katayama, T.; Northey, T.; Gawelda, W.; Milne, C.J.; Vankó, G.; Lima, F.A.; Bohinc, R.; Németh, Z.; Nozawa, S.; Sato, T.; et al. Tracking multiple components of a nuclear wavepacket in photoexcited $\mathrm{Cu}(\mathrm{I})$-phenanthroline complex using ultrafast X-ray spectroscopy. Nat. Commun. 2019, 10, 3606. [CrossRef] 
50. Leshchev, D.; Harlang, T.C.B.; Fredin, L.A.; Khakhulin, D.; Liu, Y.; Biasin, E.; Laursen, M.G.; Newby, G.E.; Haldrup, K.; Nielsen, M.M.; et al. Tracking the picosecond deactivation dynamics of a photoexcited iron carbene complex by time-resolved X-ray scattering. Chem. Sci. 2018, 9, 405-414. [CrossRef]

51. Khakhulin, D.; Lawson Daku, L.M.; Leshchev, D.; Newby, G.E.; Jarenmark, M.; Bressler, C.; Wulff, M.; Canton, S.E. Visualizing the coordination-spheres of photoexcited transition metal complexes with ultrafast hard X-rays. Phys. Chem. Chem. Phys. 2019, 21, 9277-9284. [CrossRef] [PubMed]

52. Kjær, K.S.; Van Driel, T.B.; Kehres, J.; Haldrup, K.; Khakhulin, D.; Bechgaard, K.; Cammarata, M.; Wulff, M.; Sørensen, T.J.; Nielsen, M.M. Introducing a standard method for experimental determination of the solvent response in laser pump, X-ray probe time-resolved wide-angle X-ray scattering experiments on systems in solution. Phys. Chem. Chem. Phys. 2013, 15, 15003-15016. [CrossRef] [PubMed]

53. Lawson Daku, L.M. Spin-state dependence of the structural and vibrational properties of solvated iron(II) polypyridyl complexes from AIMD simulations: Aqueous $\left[\mathrm{Fe}(\mathrm{bpy})_{3}\right] \mathrm{Cl}_{2}$, a case study. Phys. Chem. Chem. Phys. 2018, 20, 6236-6253. [CrossRef] [PubMed]

54. Britz, A.; Abraham, B.; Biasin, E.; van Driel, T.B.; Gallo, A.; Garcia-Esparza, A.T.; Glownia, J.; Loukianov, A.; Nelson, S.; Reinhard, M.; et al. Resolving structures of transition metal complex reaction intermediates with femtosecond EXAFS. Phys. Chem. Chem. Phys. 2020. [CrossRef] [PubMed]

55. Obara, Y.; Katayama, T.; Ogi, Y.; Suzuki, T.; Kurahashi, N.; Karashima, S.; Chiba, Y.; Isokawa, Y.; Togashi, T.; Inubushi, Y.; et al. Femtosecond time-resolved X-ray absorption spectroscopy of liquid using a hard X-ray free electron laser in a dual-beam dispersive detection method. Opt. Express 2014, 22, 1105. [CrossRef] [PubMed]

56. Harmand, M.; Ravasio, A.; Mazevet, S.; Bouchet, J.; Denoeud, A.; Dorchies, F.; Feng, Y.; Fourment, C.; Galtier, E.; Gaudin, J.; et al. X-ray absorption spectroscopy of iron at multimegabar pressures in laser shock experiments. Phys. Rev. B 2015, 92, 024108. [CrossRef]

(C) 2020 by the authors. Licensee MDPI, Basel, Switzerland. This article is an open access article distributed under the terms and conditions of the Creative Commons Attribution (CC BY) license (http://creativecommons.org/licenses/by/4.0/). 